\title{
Phantom structure: A representational account of floating tone association
}

\author{
Nicholas Rolle \& Florian Lionnet \\ Princeton University
}

\section{Introduction}

Floating tones are defined as tones in a representation which are not associated to a tone-bearing unit (TBU). This representation may be either part of the underlying form of a morpheme, or arise at some derivational stage. If a constraint against floating tones is ranked high enough, at a point in the derivation floating tones will be either associated to some specific TBU and realized, or will be deleted/unrealized.

This paper focuses the association of floating tones, illustrated with Bantu languages. One type is PHONOLOGICAL ASSOCIATION, where the TBU to which the floating tone associates is determined by the general phonological grammar. Typically, this can be analyzed as default/unmarked position, common examples including association to a stressed syllable, or to a TBU demarcating a domain edge (e.g. ultimate or penultimate position in a phonological word). Another type is TARGETED ASSOCIATION, where the floating tone targets some specific numerical position within a domain, e.g. a floating $(\mathrm{H})$ associates to the fourth TBU $(\tau)$ of the stem. ${ }^{1}$ Under this latter type (known in the Bantu literature as 'melodic tone'), association is idiosyncratic to the sponsoring morpheme, and does not (necessarily) target a default/unmarked position.

Marlo et al. (2015) and Paster (2019) take this latter type as evidence for counting in grammar, a position we argue against here. Instead, to account for the difference between two types of floating tone association patterns we propose a novel representation we call PHANTOM STRUCTURE. The main intuition behind phantom structure is that certain morphemes require structure to be present in order for their sponsored floating tone to be realized, but do not and cannot provide this structure themselves. We implement this representation within Optimality Theory (Prince \& Smolensky, 2004[1993]), via two partially overlapping correspondence relations (McCarthy \& Prince, 1995): one between the actual, substantive input structure and output (IO-CORRESPONDENCE), and another between phantom and output structure (PHOCORRESPONDENCE). We refer to the two inputs as the substantive plane and the phantom plane, respectively. In the input, the floating tone is actually pre-associated to a specific TBU position in the phantom plane. A simple constraint grammar requires the merger of these two input planes in the output, and results in the association of the floating tone to the equivalent numerical position in the output as in the phantom plane input.

We detail this model in what follows. The two types of floating tone associations are illustrated in section 2. Section 3 presents previous grammatical accounts of targeted association (and the implications it has for counting in grammar). Our counter proposal - phantom structure - is laid out in 4 . Alternative representational analyses are summarized and rejected in section 5, followed by a conclusion in section 6 .

\section{The issue: Two types of floating tone association}

The central issue of this paper is the association between floating tones and a TBU, focusing on two types of association. The first type we call PHONOLOGICAL ASSOCIATION, which emerges from the application of general phonological rules or constraints. Under this type, a floating tone is associated to an unmarked or default position. This is often a prominent position, e.g. a stressed TBU or a TBU at or near a domain edge.

\footnotetext{
* Thanks to our colleagues at Princeton (Laura Kalin, Byron Ahn, Sam Zukoff, Sunwoo Jeong) and Berkeley (Larry Hyman, Sharon Inkelas, Myriam Lapierre) for early feedback. We also thank the many participants at AMP 2019 who also provided valuable feedback, and the four anonymous AMP reviewers.

1 We represent floating tones as circled $(\mathrm{T}$.
} 
This is exemplified by Lamba (Bantu; Bickmore, 1995, de Lacy, 2002). In examples (1a) and (1b), Bickmore (1995) argues that the verbal root leemb 'write' and the prefix ta- NEG respectively sponsor a floating (H) in their underlying representation (the $\mathrm{H}$-sponsoring morphemes are underlined). In both cases, the sponsored floating tone associates to the initial syllable of the stress domain, which is the most prominent TBU in this environment. This happens regardless of whether the floating tone's sponsoring morph is inside (1a) or outside (1b) of the stress domain. See Bickmore (1995) for a precise definition of the stress domain.

(1) a.<smiles>[10BH]</smiles><smiles>C1CCCCC1</smiles>

tu-[lúku-leemb-a] $]_{\text {STRESS DOMAIN }}$

we-PROG ${ }_{1}$-write-FV

'we are writing'

b. (H)<smiles>C1CCCC1</smiles>

ta-tu-[ká-kom-a] $]_{\text {STRESS DOMAIN }}$ NEG-we-FUT-hurt-FV

'we will not hurt'

In contrast, the other type of association is TARGETED ASSOCIATION. Targeted association links a floating tone to some TBU which is (i) not necessarily a default position, and (ii) idiosyncratic to the morpho-syntactic feature(s) it expones and/or the morph(s) it co-occurs with. An example is from another Bantu language, Kuria (Mwita, 2008; Marlo et al., 2015; Paster, 2019). Here, inflectional TAM categories are realized by a prefix (sometimes accompanied by a suffix) and one (or two) floating $\mathrm{H}$ ) tones which idiosyncratically associate to the first, second, third, fourth, or even both to the first and fourth TBU position within the macrostem (MS). The Kuria data are quite complex. Since much of this complexity is not directly relevant to our proposal, the data we present here is slightly simplified (see Mwita 2008 in particular for extensive details).

Example (2a) below shows that the PAST PROGRESSIVE has several components (which we call subexponents): the prefix oka- PST.PROG, the perfective suffix -ey PFV, the shape of the final vowel $-e \mathrm{FV}$, and a floating $\mathrm{H}$ ) which targets the second mora (TBU) of the macro-stem (sub-exponents are underlined in the examples). ${ }^{2}$ In contrast, with the REMOTE FUtURE, the $\mathrm{H}$ ) sub-exponent targets the third mora (2b), and with the INCEPTIVE, it targets the fourth mora $(2 \mathrm{c}) .^{3}$

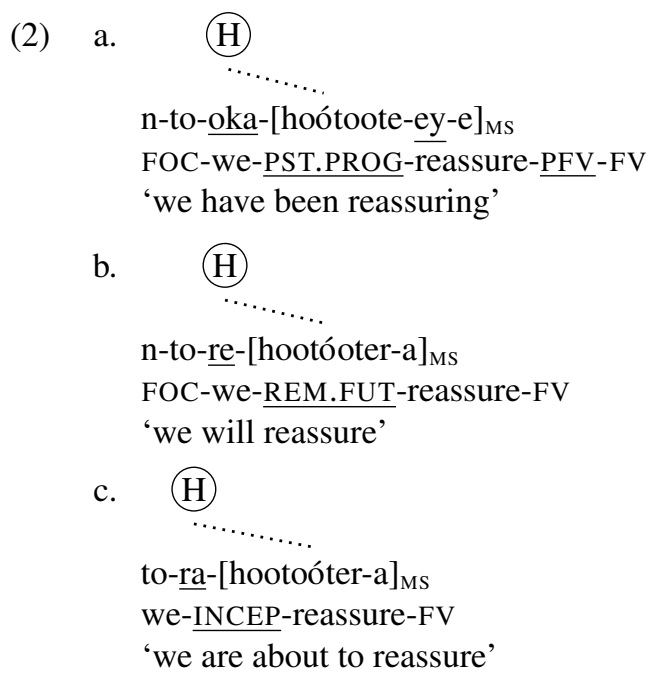

2 The TAM labels are taken from Marlo et al. (2015), and differ somewhat from the ones proposed by Mwita (2008).

${ }^{3}$ In actuality, the inceptive form involves a more complex pattern, in that the set of morphosyntactic features that assign a floating $\mathrm{H}$ to the fourth mora are sensitive to person features of the subject. With first and second person subjects, the inceptive assigns its $\mathrm{H}$ to the third mora. 
Note further that all these forms constitute hypothetical intermediate representations. On the surface, the high tone assigned in the stem always spreads to the penult, e.g. n-to-oka-hoótoote-ey-e would actually surface [n-to-oka-hoótóóté-éy-e] (and likewise [n-to-re-hootóótér-a] and [to-ra-hootoótér-a]). Since this is phonologically predictable, for the sake of brevity we ignore this tone spread rule in most of the paper, and focus on the $(\mathrm{H})$ association only.

Several other patterns exist, all morphologically idiosyncractic (cf. Odden, 1987; Cammenga, 2004; Mwita, 2008; Marlo et al., 2015). Across these patterns, there is no evidence that any these positions to which floating tones associate are phonologically unmarked and used as a default $\mathrm{H}$-associating site in Kuria. ${ }^{4}$

\section{Counting in grammar}

The targeted association patterns are relevant to debates on the status of counting in grammar. There have been several claims that human grammar cannot count, based on a variety of data and arguments (Kenstowicz, 1994:372; Smith \& Tsimpli, 1995; Hayes, 1995:307; Isac \& Reiss, 2008:65; Corbett, 2008:293; more extensive references in Paster, 2019). Smith \& Tsimpli (1995:312ff.) illustrate one such impossible system, where an emphatic element would be positioned "arithmetically rather than structurally" after the third (orthographic) word in a clause (a structure-independent operation - Chomsky, 2006:54). They demonstrated that such a pattern was not learned in an artifical language setting, neither by a polyglot savant Christopher, nor by the control group (undergraduate students of linguistics). ${ }^{5}$ Within an Optimality Theoretic context, we take this to mean that no constraint is defined so as to apply 'arithmetically' to only some $n^{\text {th }}$ member of a string. ${ }^{6}$

Given this background, Marlo et al. (2015) interpret the Kuria data above as constituting genuine evidence for counting, and thus a significant discovery for grammatical theory. Specifically, they argue that the association of $(\mathrm{H})$ to the $4^{\text {th }}$ TBU in (2c) above is direct, and not mediated by some non-counting mechanism (e.g. prosodic constituency). Paster (2019) enlarges the empirical basis of the claim that 'phonology can count' with several prosodic patterns in Eastern and Southern Bantu languages, including ternary $\mathrm{H}$ tone displacement in Sukuma i.e. $0 \mathrm{H} 000 \rightarrow 000 \mathrm{HO} 0^{7}, \mathrm{H}$ tone tripling in Manyika which "cannot be reduced to a combination" of "Penultimate Spreading, and Unbounded H Spreading" (p.16), and various ternary stress patterns (in and outside of Bantu). The counting effect in Kuria is the strongest case for counting in grammar, which Paster notes overtly (p.28). However, in any regard counting effects are extremely limited and restricted to tone and stress (p.33).

Marlo et al. (2015) and Paster (2019) criticize (mostly representational) alternatives to counting as being ad hoc, arguing that there is no independent evidence in Kuria for any of the proposed structures, for any necessary intermediate derivational steps, or for any constraints consequently needed (we return to some of these alternatives in §5). However, neither Marlo et al. (2015) nor Paster (2019) provide an explicit formalization of the counting effect.

The most advanced formalized account of the Kuria counting effect in line with these studies is Sande \& Jenks (2018), under the 'Cophonologies by Phase' (CBP) theory which integrates Cophonology Theory (Orgun, 1996; Inkelas et al., 1997; Anttila, 2002, a.o.) within Phase Theory (Chomsky, 2001; Abels, 2012, a.o.). The CBP model "relies on the application of reranked phonological constraints in particular domains," consisting of "phases, syntactic constituents that are transferred to PF during a process called Spell-Out (Chomsky, 2000, 2001)" (p.42). For example, under CBP the inceptive morpheme in Kuria is represented as in (3).

$$
[\text { T,INCEPTIVE }] \leftrightarrow\left\{\begin{array}{ccc}
\mathscr{F} & : & / \mathrm{ra}^{-} \mathrm{H} / \\
\mathscr{P} & : & {\left[{ }^{\mathrm{X}}-\right.} \\
\mathscr{R} & : & \mu 4, \operatorname{SpREAD}-(\mathrm{H}, \mathrm{R}) \gg \text { IdENT-Tone }
\end{array}\right\}
$$

\footnotetext{
4 Both phonological and targeted association of floating tones are common across Bantu. For one recent overview of some common positions of association, see Odden \& Bickmore (2014) and the papers found in that collection.

5 See also Heinz (2010), where logically possible counting patterns failed to be learned by precedence-based learners.

6 Note that 'counting' for constraint violations or harmony scores required in EVAL is different from this notion of positional counting.

7 Larry Hyman (p.c.) points out there have been numerous analyses of these Sukuma data in the literature, e.g. one in Kang (1997) which posits a pre-linked L plus floating H, without 'displacement' per se.
} 
Its (supra)segmental content ( $\mathscr{F}$, for 'feature') is $/ \mathrm{ra}^{-}{ }^{\mathrm{H}} /$ and the prosodic specification $(\mathscr{P})$ is as a $\omega$-internal prefix. Its cophonology - i.e. the partial subranking $(\mathscr{R})$ of constraints that overrules the master ranking of the phonological grammar of the language within the phase that contains the inceptive morpheme - requires two highly ranked constraints: $\mu 4$, which enforces the association of the floating $(\mathrm{H})$ to the fourth mora of the macro-stem, and SPREAD- $(H, R)$, which enforces spreading $H$ all the way to the penultimate TBU. Crucially, these are ranked higher than IDENT-TONE. The counting effect is thus formalized as a counting constraint $(\mu 4)$ directly. Consequently, other specific constraints $(\mu 2, \mu 3)$ would also be required for the other Kuria morphemes illustrated in (2) above.

\section{The proposal: Phantom structure}

We classify proposals in Marlo et al. (2015) and Sande \& Jenks (2018) as GRAMmATICAL ACCOUNTS, in that they account for the targeted association of the floating tones solely through a grammatical operation (here a constraint and constraint ranking). In fact, allowing grammar to count (here literal counting of TBUs) is inevitable in any grammatical account of the Kuria data. Our main proposal here is an alternative REPRESENTATIONAL ACCOUNT of Kuria floating tone, which maintains the more constrained assertion that natural grammars do not count. In our account, we introduce a novel representation which we call PHANTOM STRUCTURE, which does not involve counting.

Our representational account starts with the underlying structure of morphemes. Neutrally, we will refer to that phonological structure stored within the lexicon as a 'lexical entry'. Each lexical entry consists of SUbSTANTIVE StRUCture i.e. the actual phonological substance of the underlying representation(s), consisting of a string of segments and/or suprasegments (e.g. tones). A lexical entry may also contain what we term Phantom STRUCtURe, our novel type of representation. Phantom structure is phonological structure that is needed for the full realization of the lexical entry, but which the lexical entry cannot provide itself - it is a 'desire' for missing structure, so to speak. Although phantom structure is qualitatively distinct from substantive structure, phonological substance in the underlying representation can be associated to it and linearized against it.

Let us illustrate phonological substance versus phantom structure, as shown in Figure 1. The part of the underlying representation (UR) with white background is the phonological substance. For this particular lexical entry, this consists of the pre-linearized segment string /ra/ and the floating tone $/(\mathrm{H}) /$, not preassociated to a TBU within the substantive plane. This lexical entry must also contain morphosyntactic information, here an aspectual feature (the formal relation of morphosyntactic features to the phonological substance is outside the scope of this paper). ${ }^{8}$

The part of the UR with gray background is the phantom structure. For this lexical entry, this consists of a sequence of underspecified $\tau$-nodes (TBUs), which are pre-designated as being within a macro-stem constituent. The phonological substance co-occurs with pre-established relations with the phantom structure. The phonemes /ra-/ are pre-linearized to the left of this phantom string, and the floating $\mathrm{H}$ ) tone is preassociated to the $4^{\text {th }}$ TBU of the phantom structure, i.e. $/ \mathrm{ra}-\left[\bullet_{\tau} \bullet_{\tau} \bullet_{\tau} \boldsymbol{\bullet}_{\tau}\right]_{\mathrm{MS}} / .^{9}$

Note that in Figure 1, the rightmost TBU node is actually labeled $\bullet_{n}$, which is used to indicate that an unspecified number of TBUs may follow (or none at all). In the next subsection, for our purposes we ignore this node and do not include any correspondence relations with it in our analysis. We return to discussion this final $\bullet_{n}$ following that subsection.

4.1 OT implementation With the underlying structure of this lexical entry established, let us examine phantom structure in context, within an Optimality Theoretic framework. This is shown in Figure 2. This figure shows an input-output mapping, labeled at top left. Two parallel planes coexist in the input, and represent distinct strings. One is the SUBSTANTIVE PLANE and consists of phonological substance. The other is the PHANTOM PLANE and consists of phantom structure.

\footnotetext{
8 A common dichotomy in morphological theory is treating /ra- $\mathrm{H}$ / either as introducing the morphosyntactic feature directly ('incremental models' in the terms of Stump 2001), or as realizing this feature via an exponence operation ('realizational models' in Stump). Our proposal is compatible with either morphological assumption.

9 In a way, phantom structure can be understood as a representional variation on subcategorization frames (Inkelas, 1990; Zec, 2005; Bennett et al., 2018; Tyler, 2019, a.o.). This connection is made overt in Clem et al. (2019).
} 


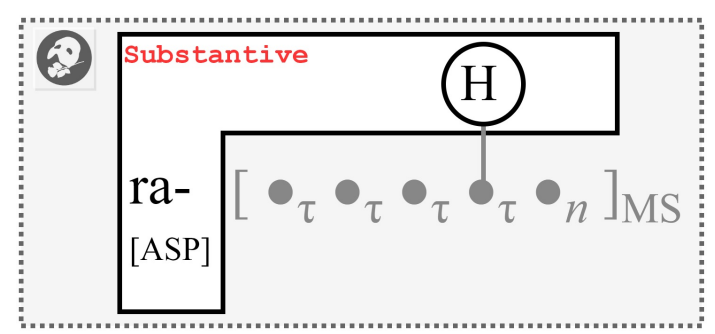

Figure 1: Phantom structure with aspectual affix /ra- $\mathrm{H} /$ in Kuria

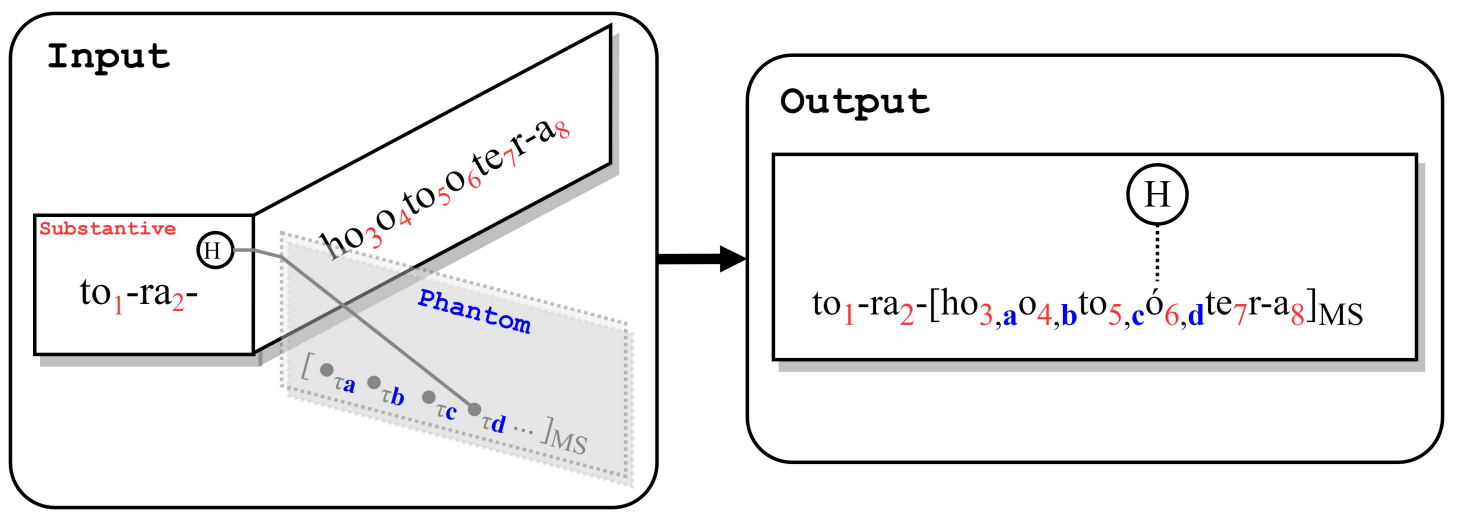

Figure 2: Phantom structure in context

As they are distinct strings, each is in a separate correspondence relation with the output candidates. Phonological computation relies on these two partially overlapping correspondence relations (McCarthy \& Prince 1995, inter alia). One is correspondence between substantive structure and outputs (CORR-SUBO), denoted with number indices (in red). The other is correspondence between phantom structure and outputs (CORR-PHO), denoted with letter indices (in blue). Standard input-output correspondence (CORR-IO) is thus split in two parallel correspondence relations.

The constraints accounting for the Kuria data are defined in (4) below.

(4) a. IDENT-PhO( $(\tau)$

Corresponding TBUs in the phantom plane (of the input) and output have identical tonal associations

b. $\operatorname{IDENT}-\operatorname{SubO}(\tau)$

Corresponding TBUs in substantive plane (of the input) and output have identical tonal associations

c. *FLOAT

Tones are associated to a TBU

d. H/HD

High tone is associated to the head of the prosodic domain ${ }^{10}$

e. $\operatorname{MAX}(\mathrm{T})$

Tones in the input have correspondents in the output

f. INTEGRITY-PHO $(\tau)$

No TBU in the phantom plane has multiple correspondents in the output

g. UNIFORMITY-PHO( $\tau)$

No TBU in the output has multiple correspondents in the phantom plane

To account for floating tone association in Kuria, these constraints must be ranked as in (5).

\footnotetext{
${ }^{10}$ The head of the macrostem domain in Kuria is the penultimate mora, which bears stress (Paster, 2019:27).
} 


\section{(5) Ident-PhO( $(\tau)$, Integrity-PhO $(\tau)$, Uniformity-PhO $(\tau)$, *FloAt, MAX(T)} $\gg \mathrm{H} / \mathrm{HD}, \operatorname{IDENT}-\mathrm{SuBO}(\tau)$

The 4th TBU in the phantom plane is pre-associated to the floating tone in the substantive plane, i.e. $\tau_{d}$ is linked to $\mathrm{H}$. Because IDENT-PHO( $\tau$ ) is ranked high, the correspondent of $\tau_{\mathrm{d}}$ must retain this association. Because the output is one-dimensional, the two planes in the input must be collapsed in the output. In essence, they are 'laid over' of one another like transparent sheets, resulting in a single composite image. The result is that the corresponding TBU with high tone is the fourth TBU of the output, i.e. [...-hootoóter-...]. In this way, the structure that is 'desired' by /ra-H)/ for the association of its floating tone is provided independently by other morphemes.

This is illustrated in the tableau in (6) below. As stated above, we ignore the phantom $\bullet_{n}$ from Figure 1 , and return to it in the next subsection.

(6) Targeted association via phantom structure in Kuria

\begin{tabular}{|c|c|c|c|c|c|c|c|}
\hline$/$ to $_{1}-\mathrm{ra}_{2}-\left\{\begin{array}{c}{\left[\bullet_{\tau \mathrm{a}} \bullet_{\tau \mathrm{b}} \bullet_{\tau \mathrm{c}} \bullet_{\tau \mathrm{d}}\right]_{\mathrm{MS}}} \\
\mathrm{ho}_{3} \mathrm{o}_{4} \mathrm{to}_{5} \mathrm{o}_{6} \mathrm{te}_{7} \mathrm{ra}_{8}\end{array}\right\} /$ & 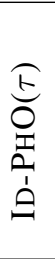 & 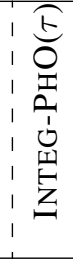 & 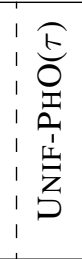 & 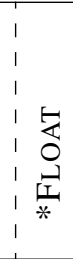 & $\overbrace{1}^{E}$ & $\stackrel{\oplus}{\Phi}$ & 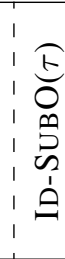 \\
\hline to $_{1}-\mathrm{ra}_{2}-\left[\mathrm{ho}_{3, \mathrm{a}} \mathrm{o}_{4, \mathrm{~b}} \text { to }_{5, \mathrm{c}} \mathrm{ó}_{6, \mathrm{~d}} \mathrm{te}_{7} \mathrm{ra}_{8}\right]_{\mathrm{MS}}$ & & I & । & । & I & $*$ & \\
\hline b. $\quad$ to $_{1}-\mathrm{ra}_{2}-\left[\mathrm{ho}_{3, \mathrm{a}} \mathrm{O}_{4, \mathrm{~b}} \text { tó }{ }_{5, \mathrm{c}} \mathrm{O}_{6, \mathrm{~d}} \mathrm{te}_{7} \mathrm{ra}_{8}\right]_{\mathrm{MS}}$ & $* !$ & I & 1 & 1 & 1 & * & $1 *$ \\
\hline c. to $_{1}-\mathrm{ra}_{2}-\left[\mathrm{ho}_{3, \mathrm{a}} \mathrm{O}_{4, \mathrm{~b}} \mathrm{to}_{5, \mathrm{c}} \mathrm{O}_{6, \mathrm{~d}} \text { té } \mathrm{ra}_{8}\right]_{\mathrm{MS}}$ & $* !$ & । & I & । & । & & $1 *$ \\
\hline d. to $_{1}-$ rá $_{2}-\left[\mathrm{ho}_{3, \mathrm{a}} \mathrm{O}_{4, \mathrm{~b}} \text { to }_{5, \mathrm{c}} \mathrm{o}_{6, \mathrm{~d}} \mathrm{te}_{7} \mathrm{ra}_{8}\right]_{\mathrm{MS}}$ & $* !$ & I & 1 & I & I & $*$ & $1 *$ \\
\hline e. to $_{1}-\mathrm{ra}_{2}-\left[\mathrm{ho}_{3, \mathrm{a}} \mathrm{o}_{4, \mathrm{~b}} \mathrm{to}_{5, \mathrm{c}} \mathrm{o}_{6, \mathrm{~d}} \mathrm{te}_{7} \mathrm{ra}_{8}\right]_{\mathrm{MS}} \mathrm{H}$ & $* !$ & I & I & । $*$ & I & $*$ & I \\
\hline f. to $_{1}-\mathrm{ra}_{2}-\left[\mathrm{ho}_{3, \mathrm{a}} \mathrm{O}_{4, \mathrm{~b}} \text { to }_{5, \mathrm{c}} \mathrm{O}_{6, \mathrm{~d}} \mathrm{te}_{7} \mathrm{ra}_{8}\right]_{\mathrm{MS}}$ & $* !$ & I & 1 & 1 & I $*$ & & $\mathrm{I}$ \\
\hline g. $\quad$ to $_{1}-\mathrm{ra}_{2}-\left[\mathrm{ho}_{3, \mathrm{a}} \mathrm{O}_{4, \mathrm{a}} \text { to }_{5, \mathrm{~b}} \mathrm{O}_{6, \mathrm{c}} \text { té } \mathrm{e}_{7, \mathrm{~d}} \mathrm{ra}_{8}\right]_{\mathrm{MS}}$ & & I $*$ & I & 1 & I & & $1 *$ \\
\hline h. $\quad$ to $_{1}-\mathrm{ra}_{2}-\left[\mathrm{ho}_{3, \mathrm{a}, \mathrm{b}} \mathrm{O}_{4, \mathrm{c}} \text { tó }_{5, \mathrm{~d}} \mathrm{o}_{6} \mathrm{te}_{7} \mathrm{ra}_{8}\right]_{\mathrm{MS}}$ & & I & I *! & I & I & * & I * \\
\hline
\end{tabular}

Undominated IDENT-PHO $(\tau)$ eliminates any candidate where $\mathrm{H}$ is not associated with $\tau_{\mathrm{d}}$ (candidates $6 \mathrm{~b}-\mathrm{f}$ ). INTEGRITY-PHO $(\tau)$ and UNIFORMITY-PHO $(\tau)$ prevent $\tau_{\mathrm{d}}$ in the input from overlapping with any TBU other

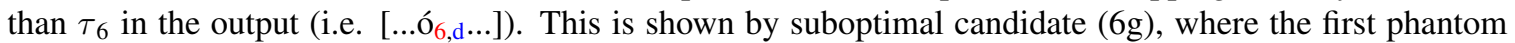
TBU $\tau_{\mathrm{a}}$ is split onto the first two substantive TBUs $\tau_{3}$ and $\tau_{4}$ of the macrostem, as well as candidate (6h), where the first two phantom TBUs $\tau_{\mathrm{a}}$ and $\tau_{\mathrm{b}}$ are merged and overlap with the first the first substantive TBU $\tau_{3}$ of the macrostem. The optimal candidate (6a) correctly assigns the floating $\mathrm{H}$ to the fourth substantive TBU $\tau_{6}$ of the macrostem, a TBU that is neither the head of the macrostem (violation of H/HD) nor underlyingly $\mathrm{H}$ (violation of IDENT-SUBO $(\tau)$ ). Crucially, it better satisfies constraints IDENT-PhO $(\tau)$, INTEGRITY-PHO $(\tau)$, and UNIFORMITY-PHO $(\tau)$.

In contrast, phonological association of floating tone as in Lamba in (1) above does not involve any phantom plane. Therefore it is not subject to $\operatorname{Ident}-\mathrm{PhO}(\tau)$, and floating tone association then is subject only to markedness constraints, in this case *FLOAT and H/HD. As a result, the floating tone associates to the least marked position (here, the stress-bearing TBU). The ranking of the relevant constraints required for Lamba is as follows:

\section{(7) $*$ FloAT, MAX(T) $\gg \mathrm{H} / \mathrm{HD} \gg \operatorname{IDENT}-\mathrm{SuBO}(\tau)$}

The tableau in (8) illustrates phonological association in Lamba (also including IDENT-PHO $(\tau)$, but note it is irrelevant). 
(8) Phonological association via default grammar in Lamba

\begin{tabular}{|c|c|c|c|c|c|}
\hline$/ \mathrm{ta}{ }_{1}-\mathrm{tu}_{2}-\left[\mathrm{ka}_{3}-\mathrm{ko}_{4} \mathrm{ma}_{5}\right]_{\text {STRESS }} /$ & 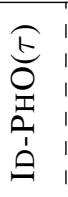 & 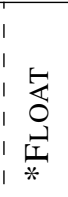 & 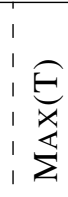 & 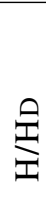 & $\begin{array}{l}\text { E } \\
0 \\
0 \\
5 \\
\sim \\
1 \\
\vdots\end{array}$ \\
\hline a. $\quad$ tá $_{1}-\mathrm{tu}_{2}-\left[\mathrm{ka}_{3}-\mathrm{ko}_{4} \mathrm{ma}_{5}\right]_{\text {STRESS }}$ & & I & I & $* !$ & $*$ \\
\hline b. ta $_{1}-\mathrm{tú}_{2}-\left[\mathrm{ka}_{3}-\mathrm{ko}_{4} \mathrm{ma}_{5}\right]_{\text {STRESS }}$ & & I & 1 & $* !$ & $*$ \\
\hline 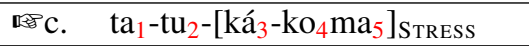 & & 1 & 1 & & $*$ \\
\hline d. $\quad \mathrm{ta}_{1}-\mathrm{tu}_{2}-\left[\mathrm{ka}_{3}-\mathrm{kó}_{4} \mathrm{ma}_{5}\right]_{\text {STRESS }}$ & 1 & I & 1 & *! & $*$ \\
\hline e. $\quad \mathrm{ta}_{1}-\mathrm{tu}_{2}-\left[\mathrm{ka}_{3}-\mathrm{ko}_{4} \mathrm{ma}_{5}\right]_{\text {STRESS }}(\mathrm{H}$ & & $* !$ & I & $*$ & \\
\hline f. $\quad \mathrm{ta}_{1}-\mathrm{tu}_{2}-\left[\mathrm{ka}_{3}-\mathrm{ko}_{4} \mathrm{ma}_{5}\right]_{\text {STRESS }}$ & & & $1 * !$ & & \\
\hline
\end{tabular}

A cumulative tableau which includes all constraints necessary for both Kuria and Lamba shows that the same ranking can account for both types. The ranking is shown in (9) and tableau in (10). The only difference is the presence of phantom structure in the case of Kuria, which induces violations of Corr-PhO constraints, which is absent in Lamba. This is only an illustrative synoptic tableau, treating the Kuria and Lamba examples as if they were part of the same language, for the sake of demonstration.

(9) Ident-PhO( $(\tau)$, Integrity-PhO( $\tau$ ), Uniformity-PhO( $(\tau)$, *FloAt, Max(T) $\gg$ $\mathrm{H} / \mathrm{HD} \gg \operatorname{IDENT}-\mathrm{SUBO}(\tau)$

(10) Synoptic tableau

\begin{tabular}{|c|c|c|c|c|c|c|c|}
\hline$/$ to $_{1}-\mathrm{ra}_{2}-\left\{\begin{array}{c}{\left[\bullet_{\tau \mathrm{a}} \bullet_{\tau \mathrm{b}} \bullet_{\tau \mathrm{c}} \bullet_{\tau \mathrm{d}}\right]_{\mathrm{MS}}} \\
\mathrm{ho}_{3} \mathrm{o}_{4} \mathrm{to}_{5} \mathrm{o}_{6} \mathrm{te}_{7} \mathrm{ra}_{8}\end{array}\right\} /$ & 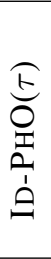 & 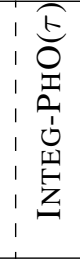 & 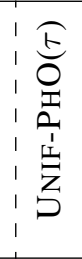 & 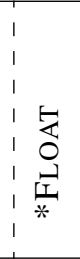 & 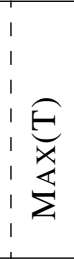 & 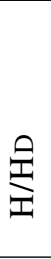 & $\begin{array}{l}\text { F } \\
0 \\
0 \\
0 \\
1 \\
1 \\
\theta\end{array}$ \\
\hline a. to $_{1}-\mathrm{ra}_{2}-\mathrm{ho}_{3, \mathrm{a}} \mathrm{o}_{4, \mathrm{~b}} \mathrm{to}_{5, \mathrm{c}} \mathrm{o}_{6, \mathrm{~d}} \mathrm{te}_{7} \mathrm{ra}_{8}$ & & 1 & 1 & i & 1 & $*$ & $*$ \\
\hline b. to $_{1}-\mathrm{ra}_{2}-\mathrm{ho}_{3, \mathrm{a}} \mathrm{o}_{4, \mathrm{~b}}$ tó ${ }_{5, \mathrm{c}} \mathrm{o}_{6, \mathrm{~d}} \mathrm{te}_{7} \mathrm{ra}_{8}$ & $* !$ & 1 & I & 1 & 1 & $*$ & $*$ \\
\hline c. to $_{1}-\mathrm{ra}_{2}-$ hó $_{3, \mathrm{a}} \mathrm{o}_{4, \mathrm{~b}} \mathrm{to}_{5, \mathrm{c}} \mathrm{o}_{6, \mathrm{~d}} \mathrm{té} \mathrm{era}_{7}$ & $* !$ & । & 1 & 1 & 1 & & $*$ \\
\hline d. $\quad$ to $_{1}-\mathrm{rá}_{2}-\mathrm{ho}_{3, \mathrm{a}} \mathrm{o}_{4, \mathrm{~b}} \mathrm{to}_{5, \mathrm{c}} \mathrm{O}_{6, \mathrm{~d}} \mathrm{te}_{7} \mathrm{ra}_{8}$ & $* !$ & 1 & 1 & 1 & 1 & $*$ & $*$ \\
\hline e. to $_{1}-\mathrm{ra}_{2}-\mathrm{ho}_{3, \mathrm{a}} \mathrm{o}_{4, \mathrm{~b}} \mathrm{to}_{5, \mathrm{c}} \mathrm{o}_{6, \mathrm{~d}} \mathrm{te}_{7} \mathrm{ra}_{8} \mathrm{H}$ & $* !$ & । & I & i $*$ & 1 & $*$ & \\
\hline f. $\quad$ to $_{1}-\mathrm{ra}_{2}-\mathrm{ho}_{3, \mathrm{a}} \mathrm{o}_{4, \mathrm{~b}}$ to $_{5, \mathrm{c}} \mathrm{O}_{6, \mathrm{~d}} \mathrm{te}_{7} \mathrm{ra}_{8}$ & $* !$ & 1 & 1 & 1 & $1 *$ & & \\
\hline g. $\quad$ to $_{1}-\mathrm{ra}_{2}-\mathrm{ho}_{3, \mathrm{a}} \mathrm{o}_{4, \mathrm{a}} \mathrm{to}_{5, \mathrm{~b}} \mathrm{O}_{6, \mathrm{c}}$ tée $\mathrm{e}_{7, \mathrm{~d}} \mathrm{ra}_{8}$ & & $* !$ & 1 & 1 & 1 & & $*$ \\
\hline h. to $_{1}-\mathrm{ra}_{2}-\mathrm{ho}_{3, \mathrm{a}, \mathrm{b}} \mathrm{O}_{4, \mathrm{c}}$ tó ${ }_{5, \mathrm{~d}} \mathrm{O}_{6} \mathrm{te}_{7} \mathrm{ra}_{8}$ & & I & I $\quad * !$ & I & I & $*$ & $*$ \\
\hline$/ \mathrm{ta} \mathrm{H}_{1}-\mathrm{tu}_{2}-\left[\mathrm{ka}_{3}-\mathrm{ko}_{4} \mathrm{ma}_{5}\right]_{\text {STRESS }} /$ & & 1 & 1 & 1 & 1 & & \\
\hline a. tá $_{1}-\mathrm{tu}_{2}-\left[\mathrm{ka}_{3}-\mathrm{ko}_{4} \mathrm{ma}_{5}\right]_{\mathrm{STRESS}}$ & & 1 & 1 & 1 & 1 & $* !$ & $*$ \\
\hline b. $\quad \mathrm{ta}_{1}-\mathrm{tú}_{2}-\left[\mathrm{ka}_{3}-\mathrm{kO}_{4} \mathrm{ma}_{5}\right]_{\text {STRESS }}$ & & 1 & 1 & 1 & 1 & $* !$ & $*$ \\
\hline c. $\operatorname{ta}_{1}-\mathrm{tu}_{2}-\left[\mathrm{ká}_{3}-\mathrm{ko}_{4} \mathrm{ma}_{5}\right]_{\text {STRESS }}$ & & । & । & I & । & & $*$ \\
\hline d. ta $_{1}-\mathrm{tu}_{2}-\left[\mathrm{ka}_{3}-\mathrm{kó}_{4} \mathrm{ma}_{5}\right]_{\mathrm{STRESS}}$ & & I & 1 & 1 & 1 & $* !$ & $*$ \\
\hline e. $\quad \mathrm{ta}_{1}-\mathrm{tu}_{2}-\left[\mathrm{ka}_{3}-\mathrm{ko}_{4} \mathrm{ma}_{5}\right]_{\text {STRESS }} \mathrm{H}$ & & । & । & $*$ ! & 1 & $* !$ & \\
\hline f. $\quad \mathrm{ta}_{1}-\mathrm{tu}_{2}-\left[\mathrm{ka}_{3}-\mathrm{ko}_{4} \mathrm{ma}_{5}\right]_{\text {STRESS }}$ & & 1 & 1 & 1 & $1 * !$ & & \\
\hline
\end{tabular}

Crucially, this analysis does not involve counting. Instead, it involves a special type of faithfulness which maintains the underlying association of tones, albeit association to a phantom TBU. In this way, this involves counting no more than the Kuria class 10 noun /itfiimbáyo/ 'hedges' (Mwita, 2008:29), which has an underlying high tone on its $4^{\text {th }}$ mora. The only difference is that in this noun, all TBUs and tones (and their association lines) constitute phonological substance, associated on the substantive plane of an input rather than the phantom plane. 
4.2 The ${ }_{n}$ node within phantom structure In Figure 1 above, we represented the lexical entry as /ra$\left[\bullet_{\tau} \bullet_{\tau} \bullet_{\tau} \bullet_{\tau} \bullet_{n}\right]_{\text {MS }}$ / with a special phantom TBU node $\bullet_{n}$. This special node has two functions. One is to allow the phantom structure to 'contort' to the shape of the substantive plane, which can be less than or more than four TBUs (see Marlo et al. (2015) for details). The subscripted $n$ may be understood as a variable which matches the number of TBUs of the substantive plane after the fourth TBU. The second function is to dictate which side of the macrostem domain is being referenced. In this representation, because $\bullet_{n}$ is located at the right edge, correspondence between the phantom and output strings begins at the left edge. As expected, numerous Bantu patterns exist which must begin correspondence at the right edge as well.

This special phantom TBU node $\bullet_{n}$ was not shown in the tableaux above, and its precise formalization falls outside of the scope of this paper. As a starting point, however, we see two possible paths towards a more refined analysis. In the first, we view $\bullet_{n}$ of the phantom structure as in correspondence with all TBUs after the fourth TBU of the output. In (11) below, $\bullet_{n}$ is in correspondence with the last two TBUs of the output.

(11) Phantom input:

Output:

$$
\begin{gathered}
\ldots\left[\bullet_{\tau \mathrm{a}} \bullet_{\tau \mathrm{b}} \bullet_{\tau \mathrm{c}} \bullet_{\tau \mathrm{d}} \bullet_{n \mathrm{e}}\right]_{\mathrm{MS}} \\
\ldots\left[\mathrm{ho}_{3, \mathrm{a}} \mathrm{o}_{4, \mathrm{~b}} \mathrm{to}_{5, \mathrm{c}} \boldsymbol{o}_{6, \mathrm{~d}} \mathrm{te}_{7, \mathrm{e}} \mathrm{ra}_{8, \mathrm{e}}\right]_{\mathrm{MS}}
\end{gathered}
$$

In this way, all TBUs in the phantom are in correspondence with some TBU in the output, and vice versa. Under this possibility, correspondence with $\bullet_{n}$ results in multiple violations of the INTEGRITY-PHO $(\tau)$ constraint which we defined above as "no TBU in the phantom plane has multiple correspondents in the output". To ensure the correct candidate wins, we would require adding another constraint which would effectively enforce correspondence. Taken altogether, this would add another function of the INTEGRITY constraint family, also used for dipthongization of monophthongs (McCarthy \& Prince, 1995:124) and reduplication of segment strings (Kurisu, 2001:30).

The other possibility would be to treat the phantom string as ... $\left[\bullet_{\tau \mathrm{a}} \boldsymbol{\bullet}_{\tau \mathrm{b}} \boldsymbol{\bullet}_{\tau \mathrm{c}} \boldsymbol{\bullet}_{\tau \mathrm{d}}\right]_{\mathrm{MS}}$, without the $\boldsymbol{\bullet}_{n}$ node entirely. Under this version, the output would be something like to $1-\mathrm{ra}_{2}-\left[\mathrm{ho}_{3, \mathrm{a}} \mathrm{O}_{4, \mathrm{~b}} \mathrm{to}_{5, \mathrm{c}} \mathrm{o}_{6, \mathrm{~d}} \mathrm{t} \mathrm{e}_{7} \mathrm{ra}_{8}\right]_{\mathrm{MS}}$, where the final two TBUs have no correspondent in the phantom string. From the perspective of the phantom plane this would constitute epenthesis, and therefore such structure requires a constraint $\mathrm{DEP}-\mathrm{PHO}(\tau)$ to be ranked low for it to be optimal. In our tableaux, we have essentially employed this latter version, but wish to make no endorsement here over its competitor.

\section{Against alternative accounts}

In this section, we provide arguments against several alternative accounts. Several of these arguments were previously made by Marlo et al. (2015) and Paster (2019), which we cite when appropriate.

5.1 Arguments against floating (L)(L)(L)(H) sequence One alternative to both phantom structure and counting is to posit a floating tone sequence /ra-(L)(L)(L)/H)/. This was originally argued for in Cammenga (2004), and was recently defended by Trommer (2019). Marlo et al. (2015:260-262) originally rejected this analysis, on the basis of three convincing arguments. First, the sequence of floating (L) tones would constitute multiple violations of OCP, and therefore represents a highly unusual (and unlikely) structure under normal assumptions in autosegmental theory. Second, the Kuria tone system is best analyzed as a H vs. $\emptyset$ system, with $\mathrm{L}$ being inserted late only as default. Positing underlying $\mathrm{L}$ tones to solve the counting problem is thus both uneconomic and $a d-h o c$. Finally, later $\mathrm{H}$ tone spreading operations spread into the hypothetical (L) (L) (D) (H) sequence, which one would expect to be blocked if there were bona fide $\mathrm{L}$ tones in the representation. This is illustrated in (12) below, where the $\mathrm{H}$ tone of the negative prefix /tó-/ spreads rightward into the macrostem, across the infinitive prefix /ko $\mathrm{H} /$, which itself assigns a $\mathrm{H}$ ) to the fourth mora of the macrostem (targeted association) (Paster, 2019:27-28).

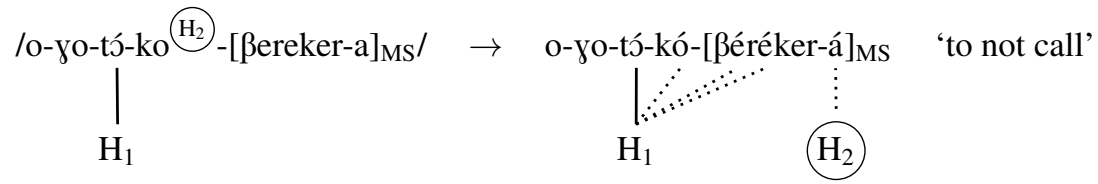


5.2 Argument against metrical structure Another analysis eschewing the need for both counting and phantom structure is metrical structure, put forward and rejected in Marlo et al. (2014, 2015). The arguments against it are summarized in Paster (2019:26-27). The main argument is that the different positions to which floating tones are assigned would require the definition of several metrical constituents with conflicting properties. Indeed, any of the positions targeted by $(\mathrm{H})$ association can be defined in metrical terms: $\tau_{1}$ would be the head of the left-headed moraic foot $\left(\dot{\mu}_{s} \mu_{w}\right), \tau_{2}$ (2a) would be a right-headed moraic foot $\left(\mu_{w} \mu_{s}\right), \tau_{3}(2 \mathrm{~b})$ would be the head of a non-extrametrical left-headed moraic foot within a two-foot colon $\left[\langle(\mu \mu)\rangle\left(\dot{\mu}_{s} \mu_{w}\right)\right]$, and $\tau_{4}(2 \mathrm{a})$ would be the head of a non-extrametrical right-headed moraic foot within a two-foot colon $\left[\langle(\mu \mu)\rangle\left(\mu_{w} \dot{\mu}_{s}\right)\right]$. However, since all of these positions can be targeted in one and the same language, it is impossible to resort to metrical structure without allowing for conflicting parses; no default metrical structure exists. Some of the Kuria patterns not illustrated in this paper even involve the targeted association of two $\mathrm{H}$ to two distinct positions within the macrostem, viz. to the first and fourth simultaneously, as with the combination of the inceptive prefix and a third person plural subject prefix, illustrated in (13) (ignoring H-spread). Such patterns require "conflicting metrical parses to coexist within a single word" (Paster, 2019:27).

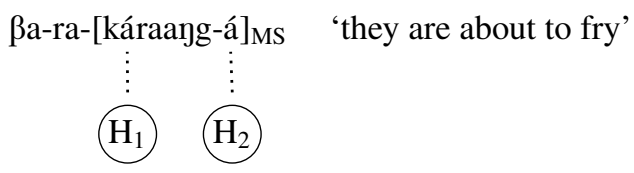

5.3 Argument against deficient structure One last alternative is rather than phantom structure in the underlying representation of the $\mathrm{H}$-associating prefixes, instead there would be segmentally deficient structure, such as 'ghost segments', or empty prosodic categories commonly used in the analysis of reduplication (Archangeli, 1991; Zoll, 1996; Saba Kirchner, 2010; Zimmermann, 2019; see extensive references within last two). The inceptive morpheme would then be analyzed as /ra $\bullet_{\tau} \bullet_{\tau} \bullet_{\tau} \boldsymbol{\bullet}_{\tau} /$ with a $\mathrm{H}$ tone pre-associated to a segmentally-deficient TBU. Like phantom structure, ghost structure is segmentally empty. The crucial difference is that, contrary to phantom structure, ghost elements are in the same plane as substantive elements (they are deficient substance), hence subject to the same input-output correspondence relation.

The main argument against this approach is that the TBUs in the phantom structure do not show the expected behavior of ghost structure. They are (i) not realized in order to avoid markedness violations, (ii) not deleted to avoid markedness, (iii) never realized with a latent segment, and (iv) never realized via epenthesis or reduplication (e.g. /to-ra $\bullet_{\tau} \bullet_{\tau} \bullet_{\tau} \boldsymbol{\bullet}_{\tau}$-hootooter-a/ $\rightarrow *$ to-ra-[hootoó] $]_{\text {RED }}$-hootooter-a). Such a reduplicative pattern is not attested anywhere in Kuria, or in the extensive Bantu literature on floating tone. In short: phantom structure is not substance in the input.

\section{Conclusion}

This paper contrasted two types of floating tone association, one attributable to the general phonological grammar, and another which targets a specific position for association. 'Targeted' floating tone association poses a crucial problem to phonological theory: it allows the grammar to count, such as requiring a high tone on the second, third, or fourth TBU of a domain. All previous representational analyses have been shown to be ad hoc and unconvincing, leading to proposals involving a grammatical account, for example directly employing a counting constraint (e.g. $\mu 4$ in Sande \& Jenks (2018)).

In contrast, this paper introduced phantom structure, a novel kind of tonal representation meant to account for targeted association without resorting to counting. We proposed an Optimality-theoretic implementation of phantom structure relying on a split of the traditional Input-Ouput Correspondence into two sets of correspondence relations: Substantive Input-Output (SO), and Phantom Input-Output (PhO) correspondence. The theory was necessarily only briefly exposed here. Future research will explore and further develop the nature of phantom structure, its relation with substantive structure, its grammatical implementation, and the typology of phenomena that it can aptly account for. 


\section{References}

Abels, Klaus (2012). Phases: An essay on cyclicity in syntax. de Gruyter, Berlin.

Anttila, Arto (2002). Morphologically conditioned phonological alternations. Natural Language and Linguistic Theory 20:1, 1-42.

Archangeli, Diana (1991). Syllabification and prosodic templates in Yawelmani. Natural Language \& Linguistic Theory 9:2, 231-283.

Bennett, Ryan, Boris Harizanov \& Robert Henderson (2018). Prosodic smothering in Macedonian and Kaqchikel. Linguistic Inquiry 49:2, 195-246.

Bickmore, Lee S. (1995). Tone and stress in Lamba. Phonology 12:3, 307-341.

Cammenga, Jelle (2004). Igikuria phonology and morphology: A Bantu language of south-west Kenya and north-west Tanzania. Köppe.

Chomsky, Noam (2000). Minimalist inquiries. Martin, Roger, David Michaels \& Juan Uriagereka (eds.), In Step by step: Essays on minimalist syntax in honor of Howard Lasnik, MIT Press, Cambridge, Mass.

Chomsky, Noam (2001). Derivation by phase. Kenstowicz, Michael (ed.), Ken Hale: A life in language, MIT Press, Cambridge, Mass., 1-52.

Chomsky, Noam (2006). Language and mind. Cambridge University Press.

Clem, Emily, Virginia Dawson \& Nicholas Rolle (2019). Post-syntactic altruism. Handout of a paper presented at the 50th Meeting of the North East Linguistic Society, 26 October 2019.

Corbett, Greville G. (2008). Determining morphosyntactic feature values. Case and grammatical relations: Studies in honor of Bernard Comrie 1-34.

Hayes, Bruce (1995). Metrical stress theory: Principles and case studies. University of Chicago Press.

Heinz, Jeffrey (2010). Learning long-distance phonotactics. Linguistic Inquiry 41:4, 623-661.

Inkelas, Sharon (1990). Prosodic Constituency in the Lexicon: Outstanding Dissertations in Linguistics Series. New York: Garland Publishing Co.

Inkelas, Sharon, C. Orhan Orgun \& Cheryl Zoll (1997). The implications of lexical exceptions for the nature of grammar. Roca, Iggy (ed.), Derivations and Constraints in Phonology, Oxford University Press, Oxford and New York, 393418.

Isac, Daniela \& Charles Reiss (2008). I-Language. An INtroduction to Linguistics as Cognitive Science. Oxford university Press, Oxford, UK.

Kang, Yoonjung (1997). Tone in sukuma. MIT Working Papers in Linguistics 30, 49-95.

Kenstowicz, Michael J. (1994). Phonology in generative grammar, vol. 7. Blackwell Cambridge, MA.

Kurisu, Kazutaka (2001). The phonology of morpheme realization. PhD Thesis, University of California, Santa Cruz.

de Lacy, Paul (2002). The interaction of tone and stress in Optimality Theory. Phonology 19:1, 1-32.

Marlo, Michael R., Leonard Chacha Mwita \& Mary Paster (2014). Kuria tone melodies. Africana Linguistica 20, 277_294.

Marlo, Michael R., Leonard Chacha Mwita \& Mary Paster (2015). Problems in Kuria H tone assignment. Natural Language \& Linguistic Theory 33:1, 251-265.

McCarthy, John J. \& Alan Prince (1995). Faithfulness and reduplicative identity. Linguistics Department Faculty Publication Series p. 10.

Mwita, Leonard Chacha (2008). Verbal tone in Kuria. PhD Thesis, University of California, Los Angeles.

Odden, David (1987). Predicting tone in Kikuria. Current approaches to African linguistics 4, 311-326.

Odden, David \& Lee Bickmore (2014). Melodic tone in Bantu: overview. Africana Linguistica 20, 3-13.

Orgun, C. Orhan (1996). Sign-based morphology and phonology, with special attention to optimality theory.

Paster, Mary (2019). Phonology counts. Radical: A Journal of Phonology 1, 1-61.

Prince, Alan \& Paul Smolensky (2004[1993]). Optimality Theory: Constraint interaction in generative grammar. Blackwell, Malden, MA, and Oxford, UK.

Saba Kirchner, Jesse (2010). Minimal reduplication. PhD Thesis.

Sande, Hannah \& Peter Jenks (2018). Cophonologies by phase. Proceedings of NELS 48, University of Iceland 3, 39-53.

Smith, Neilson Voyne \& Ianthi-Maria Tsimpli (1995). The mind of a savant: Language learning and modularity. Blackwell Publishing.

Stump, Gregory T. (2001). Inflectional Morphology: A Theory of Paradigm Structure. Cambridge University Press., Cambridge.

Trommer, Jochen (2019). Lexically conditioned phrasal tone. Handout of a paper presented at SinFonIJA 2019, Brno, September 2019.

Tyler, Matthew (2019). Simplifying MATCH WORD: Evidence from English functional categories. Glossa: a journal of general linguistics $4: 1$.

Zec, Draga (2005). Prosodic differences among function words. Phonology 22:1, 77-112.

Zimmermann, Eva (2019). Gradient Symbolic Representations and the Typology of Ghost Segments. Proceedings of the Annual Meetings on Phonology, vol. 7.

Zoll, Cheryl Cydney (1996). Parsing below the segment in a constraint based framework. PhD Thesis, UC Berkeley. 